Fecha de recepción: septiembre 2009 Fecha de aceptación: octubre 2009 Versión final: noviembre 2009

\section{Patrimonio, historia y diseño de los jardines del Palacio San José \\ Edgardo M. Ruiz *}

\begin{abstract}
Resumen: El Palacio San José, propiedad del General Urquiza en Entre Ríos, ha dejado testimonios de la historia paisajística del siglo XIX de Argentina. Sus parques y jardines son la evidencia de un período donde la reproducción de modelos paisajísticos europeos en América marcaron una época. La composición simétrica del palacio conformó diversos jardines: los dos patios interiores, el jardín francés, el parque posterior, el parque exótico y el lago artificial; todo dispuestos proporcionalmente al eje este-oeste propuesto por la construcción. Aquí se presenta una hipótesis en relación a la denominación del jardín ingles y se dan pautas que apuntan a una disposición toscana más que francesa. Así mismo su legado se extiende al ámbito botánico, dado que San José fue uno de los más importantes centros de aclimatación de especies vegetales del país. Llegaban hasta aquí vegetación y semillas provenientes de Brasil, Paraguay, Montevideo, Buenos Aires y Europa, de obsequio o compras del propio Urquiza, quien valoraba y fomentó como Gobernador la agricultura y la educación botánica en su provincia. La composición de los jardines y las especies vegetales que formaban los jardines de la Estancia San José son un patrimonio nacional que merece ser investigado.
\end{abstract}

Palabras claves: Urquiza - Palacio San José - Jardines históricos - Patrimonio paisajístico - Aclimatación de especies.

[Resúmenes en inglés y portugués y currículum en la página 211]

\title{
Patrimonio cultural
}

En la 17a reunión de la Conferencia General de la Organización de las Naciones Unidas para la Educación, la Ciencia y la Cultura, ocurrida en París, el 17 de octubre de 1972, se estipularon las consideraciones del "Patrimonio cultural" y el "Patrimonio natural". Uno de los axiomas que reseñan al patrimonio cultural hace referencia a "los lugares como obras conjuntas del hombre y la naturaleza con valor especial por su belleza o su interés desde el punto de vista arqueológico, histórico o científico". La protección patrimonial en la República Argentina toma forma en 1940, cuando Ricardo Levene inspiró la ley No 12.665 creando la Comisión Nacional de Museos, Monumentos y Lugares Históricos.

Hace no mucho tiempo en Argentina, se viene trabajando en la protección del patrimonio cultural no solo con la protección de la arquitectura, sino también de su entorno natural, centrando la idea en el conjunto, en las áreas históricas, incluyendo a la naturaleza construida dentro de este tipo de noción patrimonial.

Previo a estas políticas de resguardo y patrimonio, en 1935 la ley No 12.261 declaró Monumento Nacional al Palacio San José, sus accesos y sus jardines, disponiendo la instalación de un museo regional. Fue el Palacio San José la residencia particular del General Justo José de Urquiza, ubicada a treinta 
kilómetros de la ciudad de Concepción del Uruguay, en la Provincia de Entre Ríos, República Argentina. Los parques del Palacio San José manifiestan hoy un caso particular de patrimonio natural diseñado del siglo XIX, siendo singular, ya sea por el estilo compositivo de los jardines, tanto como por la valoración botánico de las especies que conforman el parque.

\section{Justo José de Urquiza y su admiración por la vegetación}

El propietario, Justo José de Urquiza, es la persona que forjó la construcción del Palacio San José en 1848, e impulsó la creación de los jardines en donde se adaptaron especies exóticas y productivas. La vegetación foránea era adquiría por él, o recibía de obsequio: "La sensibilidad de Urquiza por la naturaleza era tal que quienes lo conocían sabían que una forma de establecer buenas relaciones con él era a través del obsequio de una planta rara que aumentara su colección botánica"'.

Urquiza se relacionó con diversos comerciantes y naturalistas que se encargaron de proporcionarle las especies vegetales que jerarquizaron los parques y jardines del palacio. El propio Urquiza facultaba a sus representantes comerciales para la comprar de retoños y semillas. Uno de los lugares donde adquiría especies vegetales era la quinta de José Gregorio Lezama, en la zona sur de Buenos Aires. En el Museo Palacio San José, en el archivo histórico hay documentos que narran mencionadas compras...

El jardinero va pa. Bs. As. á arreglar algunos negocios particulares S. E. le dá la comision de comprarle algunas semillas y plantas de flores en la (casa) quinta del Sor. Lezama, á quien ordena S. E. se dirija U. i al Sor. Taurel pa. que se las venda, y á este último pa. que también abone el importe de la compra de aquellas... ${ }^{2}$.

El mencionado Señor Manuel Taurel era el secretario comercial de Urquiza.

Para el siglo XIX en la Argentina se hallaban dos lugares importantes de aclimatación de especies vegetales: La quinta de Gregorio Lezama, en Buenos Aires, y el Palacio San José, cercano a Concepción del Uruguay, en Entre Ríos.

En estos centros experimentales se realizaban las reproducciones de especies foráneas tanto para prácticas utilitarias como estéticas. El naturalista Eduardo Holmberg proporcionó ejemplares y asesoramiento en los cuidados y cultivos de numerosas especies vegetales provenientes de su quinta particular de Buenos Aires: "Entre las plantas compradas a Holmberg figuran parras chasellas de Fontainebleau, moscatel de España y otras. En una nota de plantas enviadas en mayo de 1860 figuran pinos teocoté, ciprés lambertiana, Santa Rita, dracena y algunos frutales"3.

El médico y naturalista Aimé Bomplad, llego al Rió de la Plata para comienzos de siglo y luego se establece en la Provincia de Corrientes. Urquiza acude a sus servicios médicos en julio de 1950 en busca de un remedio para su ejército que padecía una epidemia de disentería. De esta manera comienza una amistad que se vigoriza con el envió de semillas y plantas para incorporarse el acerbo botánico del palacio.

Desde diversas partes se recibían plantas y semillas para San José: desde Montevideo el comerciante Agustín de Castro, desde Mendoza por José María Pacheco, desde Europa, se les requerían al mariscal Andrés de Santa Cruz, encargado de los negocios de Urquiza en París. Varias citas más se podrían hacer acerca de las compras de especies vegetales para los jardines del palacio, todas manifestadas a través de diversas facturas y contratos de compras que se encuentran en el archivo del Museo del Palacio San José. 
Las relaciones comerciales y los contactos políticos de Urquiza le han dado la posibilidad de acceder a plantas realmente particulares.

En un estudio de Plantas cultivadas en el Palacio San José en vida del General Justo José de Urquiza figura dentro de las especies ornamentales la palma real (Roystonea regia), esta palmera fue traída al continente americano desde la isla Mauricio, del jardín de Pamplenousse, por Luiz de Abreu Vieira e Silva en 1809, para el Rey Don Juan VI (del reino de Portugal, Brasil y Algarves). Este único ejemplar fue colocado en el Jardín Botánico de Río de Janeiro, Brasil. El espécimen a sido celosamente custodiada al florecer: "En 1828 florece por primera vez. Serpa Brandao, director de aquella época mando capturar y quemar los frutos para reservar al Jardín Botánico el monopolio de aquel vegetal plantado por las manos reales"4. No se tiene conocimiento del recorrido de esta especie hasta su llegada a los jardines del palacio, empero se podría conjeturar que pudo ser un obsequio de Pedro II.

Repasando la historia argentina y brasileña, las relaciones políticas y comerciales entre los entrerrianos, al mando de su gobernador Justo José de Urquiza, y los brasileños fueron asiduas; Brasil y Entre Ríos formaron parte de la alianza que derrotó al Gobernador de Buenos Aires, Juan Manuel de Rosas, en la batalla de Caseros en febrero de 1852. Así mismo estos contactos se sostenían con regalos entre gobernantes. En un artículo sobre los parques de estancias figura un apartado sobre San José donde se destaca un aporte del emperador brasileño para los parques de Urquiza: “...se destaca el alcornoque que, según la tradición, le fue obsequiado a Urquiza por el emperador de Brasil Pedro II”s.

La presunción del obsequio de la palmera real a Urquiza por el gobernante brasileño podría ser auténtica, al ser una especie celosamente custodiada, e incluso se narra que llegaban de Brasil pájaros exóticos para las pajareras del Palacio San José.

La valoración botánica de los jardines de San José es verdaderamente significativa, los ejemplares extranjeros eran adaptados en los invernaderos del parque y cultivados en él. Las dimensiones de los jardines eran imponentes., en el libro Palacio San José Patrimonio Botánico se detalla un inventario de los árboles cultivados:

...88 granados, 759 naranjos, 6.476 duraznos, 78 damascos, 569 perales de varias clases, 240 manzanos, 41 almendros, 89 ciruelas, 21 cerezos, 32 nogales, 80 nísperos, 44 guindos, 14.700 membrillos, 495 higueras de varias clases, 226 parras... Además,... 1.550 álamos, 2.100 sauces, 586 paraísos, 71 mimbres... ${ }^{6}$.

Este inventario no tiene fecha de efectuado, pero en él se destacan las especies productivas y luego una serie de especies ornamentales del parque.

La vegetación es la esencia del diseño de los parques de esta estancia tan particular. La composición de los diversos jardines dan señal de una época y destacan la opulencia y la imponente personalidad de un destacado personaje y gobernante de la historia Argentina, el General Justo José de Urquiza.

\section{El diseño de los patios, jardines y parques del palacio San José}

\section{Construcción del palacio y patios interiores}

El paisaje entrerriano esta compuesto por suaves llanuras onduladas cubierta de altos pastizales donde los árboles crecen en torno a los ríos y arroyos de la región. El palacio San José se instaló en la punta de la loma próxima al rió Gualeguaychu. La estancia se dispuso con su entrada principal mirando 
al este; era usual en las fincas de la zona la orientación al este para poder contar con el beneficio de la suave brisa que de allí procede. Esta disposición compositiva de la construcción generó un eje axial este-oeste, repartiendo las construcciones y los parques en forma proporcional a ambos lados.

El primer constructor del que se tiene referencias es Jacinto Dellepiane y no como se cree el Arquitecto Pedro Fosatti, que llegará mas tarde cuando la mayoría de las construcciones están ya terminadas. Las construcciones se inician en 1948 con un primer cuerpo cuadrangular de estilo pos-colonial, con fuertes rejas, peanas y dos torres miradores cuadradas que rematan en forma octagonal.

No hay fechas exactas de las construcciones, empero, la incorporación del segundo conjunto y el bloque de servicio, sería próxima a los años 1853 y 1854. Esta hipótesis se fortalece al incorporarse el dato del casamiento de Urquiza con Dolores Costa, formalizando una familia que se consumaría con once hijos, viéndose así en la necesidad de ampliar la residencia.

El segundo cuerpo presenta un estilo proto-moderno fiel a los ideales de su propietario. La vivienda quedó constituida por treinta y ocho habitaciones con dos grandes patios y solo dos entradas, ubicadas sobre el eje principal este-oeste de la composición. Otras construcciones que se instalaron fueron: dos cobertizos para carruajes, dos palomares, la tahona y la panadería, y del otro lado la pulpería, todo en el llamado patio trasero.

La participación del Arquitecto Pedro Fosatti se precisa en 1857. Este arquitecto realiza la capilla y remoza todas las construcciones. El frente posee una galería con siete arcos que se abaten sobre columnas de estilo toscano.

El primer patio al que se accede es el patio de honor, con detalles de reminiscencia italiana con columnas y mármoles.

El segundo patio, o patio del parral, conserva hoy un solo aljibe, pero se presume que hubo otro, ubicado en forma simétrica. Sobre este patio Fosatti incorpora una galería de hierro forjado construida por Tomas Benvenuto, inmigrante italiano con residencia en Buenos Aires. Estos herrajes no solo serviría para que las parras trepen, sino que también ocultaban las asimetrías de la construcción, debido a la ausencia de ventanas y puertas de forma simétrica o a sus diferentes alturas en todos los frentes del patio.

Entorno a la vivienda y sus patios internos se dispusieron jardines compartimentados que completan el complejo del Palacio San José.

\section{Jardín exótico}

Es este el primer parque de acceso a la residencia, el más amplio y el que envuelve a todos los demás jardines. Aquí se ubicaban las especies foráneas que llegaban a San José, por ende su nombre de exótico. Su composición remite a una plantación en cuadricula de cinco metros por cinco metros, esto se puede valorar en el terreno. Sobre esta disposición se cultivaban de igual forma plantas exóticas como frutales, ubicándose las exóticas mas próximas a la casa. En la actualidad quedan pocos árboles pero se aprecian claramente el ordenamiento en cuadrícula.

Los jardines del palacio llamaban la atención a cuanto visitante se acercara quizás en busca de la barbarie del caudillo del interior, y en oposición encontraba parques, patios y jardines finamente diseñados al mejor estilo de los parques y jardines europeos.

Una de estas personas fue Alfredo M. Du Graty quien dejara un testimonio gráfico importante al publicar en 1858 en París el libro La Confederación Argentina en donde se divulgó un grabado de los edificios y los jardines del Palacio San José. Sobre este personaje escribe Juan de Dios Muñoz: "El aristócrata belga Alfredo Du Graty llegó a la Argentina en 1.850. Había realizado estudios militares en Bruselas y 
poseía una notable cultura..."7. Du Graty llega a ser Director del Museo Nacional de Historia Natural en Paraná, en el momento en que Urquiza es Presidente de la Confederación. Lo mas destacado del militar belga, es el grabado editado en su libro donde (con su conocimiento de la perspectiva) revela las plantaciones en cuadriculas; también en ese grabado se aprecian las norias que recogían el agua de lluvia que se utilizaba para regar a balde los cultivos. Otro detalle manifiesto en la imagen son los dos pequeños invernaderos a ambos lados del camino, utilizados para la aclimatación de vegetales foráneos.

Igualmente, en la parte posterior hay detalles que no quedan claros en el grabado de Du Graty, dado que presentan algunas alteraciones como la capilla que no es la existente, o el excelso camino que cruza la parte trasera de los jardines que no es ni fue así.

Este enorme jardín se consuma con el camino de acceso flanqueado de magnolias (Magnolia grandiflora), grevileas (Grevillea robusta), encinas (Quercus ilex), alcornoques (Quercus suber), ombúes (Phytolacca dioica), cicas (yica reboluta), araucarias (Araucaria angustifolia), cipreses (Cupressus sempervirens), pino piñonero (Pinus pines), palmeras pindó (Arecastrum romanzoffianum), entre barias especies de cultivo comercial.

Queda por último destacar el ornato del jardín con las dos grandes pajareras de fino herraje y mármol de carrara dispuestas equilibradamente a ambos lados del camino. Estas pajareras de hierro forjado con enrejado en cobre con vidrio para ambientar especies tropicales, fueron realizadas por el italiano Tomas Benventto en Buenos Aires para ser instaladas aquí. La prensa en 1867 expresaba las sensaciones de este paisaje: “...Una elegante pajarera llena de pájaros cantores se eleva en medio de esta vegetación pomposa y embalsamada y el oído no menos que la vista se embelesan...”.

Por último se destacan una fuente de hierro fundido en el centro del camino de lajas y las dos esculturas en los pilares de la puerta de entrada simbolizando a los continentes de Europa y África.

\section{Jardín francés}

El jardín delantero se encuentra encerrado por una reja artística realizada por Francisco Carulla, otro herrero italiano, y es llamado el "jardín francés", quizás por su excesiva simetría y sus parterres de formas equilibradas.

Aquí se nos plantea la necesidad de cuestionar la denominación de jardín francés, partiendo de ciertas sensaciones, conceptos y hechos que apuntan a la hipótesis de que éste espacio esté inspiración en los jardines toscanos más que en la jardinería francesa:

1. La noción de jardín francés parte de la disposición proporcional de los canteros, hecho que ya ocurría en los primeros jardines renacentistas de Florencia, así se describe en el libro de Francisco Páez de la Cadena: “...concentrados alrededor de un eje básico y que generalmente respondía a la prolongación del propio eje de la edificación principal...” este planteo se valora con claridad en San José.

2. Las dimensiones de este jardín no se reconoce con las amplias extensiones de la jardinería francesa, y sí se semejan a las proporciones mas reducidas de los espacios ajardinados del renacimiento italiano; solo recordar que los jardines italianos son la consecuencia inmediata de la liberación de los cerrados jardines medievales, siendo sus dimensiones más acotadas y similares a las que se manejan en este espacio entrerriano.

3. Otra sensación que apunta a un jardín italiano, se funda en la ornamentación recargada de su composición, utilizando estatuas, fuentes para peces, copones con plantas, diversos solados, rejas trabajadas, esculturas; todas estas aplicaciones ornamentales se utilizaron con exceso en los jardines de la región Toscana. 
4. Por último, si el embellecimiento de la residencia correspondió al arquitecto toscano Pedro Fosatti y en el frente del edificio se instalaron columnas toscanas, esto podría sustentar la postura de ser este un jardín inspirado en ideas italianas de la región toscana más que imágenes francesas.

Al margen de estos imaginarios este jardín realza la edificación con canteros armónicos y estéticos cultivados con plantas de floraciones coloridas. En el libro editado por el Museo San José se relata sobre las especies cultivadas: "En los canteros se renueva periódicamente la plantación de flores de estación tales como pensamientos (Viola tricolor), caléndulas (Caléndula sp.), petunias (Petunia), copetes (Tagete sp.), conejitos (Antirrhinum sp.), etc..."10.

Este jardín se completa con una serie de especies arbóreas y arbustivas destacadas: boj (Boxus sempervirens), magnolias (Michelia fuscata), azaleas (Rhododendron indicum), fuschia (Fuschia magellanica), Santa Rita (Bougainvillea spectavilis), diversas rosas y palmeras washingtonia (Washingtonia filifera), entre diversas especies.

Este jardín se concluye con diversas ornamentaciones: dos estanques a ambos laterales que podrían haber tenido peses por su gran profundidad, también se encontraban copones con vegetación sobre las pilastras del perímetro, y por ultimo, sobre los pilares del portón de acceso que separa el jardín exótico de este se encuentran las estatuas de mármol italiano de África y Europa.

Este jardín es sin duda el más llamativo de todos destacándose por su colorido y disposición ordenada, enmarcando la entrada al gran palacio de Urquiza.

\section{Jardín posterior}

Este jardín se encuentra en la parte trasera y se accede o por la residencia o por el acceso de servicio lateral, siendo el único patio con dos caminos que se cruzan. Estas calles fueron cubiertas por lajas como gesto de la modernidad impulsada por Urquiza, dejando de lado la tierra y la polvareda, accediendo a su residencia a través de un camino refinadamente consolidado.

Sobre este jardín se escribe: "En los bordes de la avenida del jardín posterior, como límite de las áreas parquizadas con ejemplares arbóreos y arbustivos, se ubican copones de mármol y los bustos de cuatro conquistadores (Alejandro Magno, Hernán Cortes, Julio Cesar y Napoleón)" ${ }^{11}$. Los copones que relata la crónica llevan la inscripción de Dolores de Urquiza, esposa del General.

El ingreso posterior (lateral) ha sido el utilizado cotidianamente y fue realizado para el ingreso de los carruajes contando con la posibilidad de depositar a los invitados y residentes bien próximos al acceso posterior del palacio sobre el camino enlajado. La importancia de este camino lo sellan las esculturas de los conquistadores y otras dos esculturas (La primavera y El otoño), todas miran hacia este ingreso lateral, hacia el norte, a diferencia de toda la composición que se dispone proporcionalmente sobre el camino principal de este a oeste.

Otra pauta de la jerarquía de esta entrada lo pautan las especies vegetales dispuestas: tuyas (Thuja orientalis), alcornoque (Quercus suber), diversas palmeras (Washingtonia filifera, Phoenix canariensis, Arecastrum romanzoffianum), cicas (Cyca revoluta), jacarandaes (Jacaranda mimosifolia), grevileas (Grevillea robusta), caquis (Diospyros kaki), estrellas federal (Euphorbia pulcherrima), rosas (Rosas sp), azaleas (Rhododendron indicum), etc.

En este jardín la gran mayoría de las especies son meramente ornamentales manifestando la importancia del patio trasero. 


\section{Lago artificial}

La última disposición en el trazado es el lago artificial, ubicado más allá del patio trasero al oeste. La calle de tierra que va del patio posterior y que continúa el eje central este-oeste hasta llegar a orillas del lago se halla acompañada a ambos lados por alineaciones de álamos carolinos (Pópulus angulata). Sobre este parque se relata:

...la casa tenía otro lugar de solaz para el paseo y el disfrute de la vida al aire libre. Un lago artificial, construido muy cerca de la casa, fue la última gran obra construida en San José. Tenía una extensión de $180 \mathrm{~m}$. de largo por $120 \mathrm{~m}$. de ancho y $5 \mathrm{~m}$. de profundidad. El agua que lo alimentaba se traía de una laguna cercana a través de cañerías y por bombeo ${ }^{12}$.

La construcción del lago requirió de la realización de un tajamar próximo al río Gualeguaychu para la obtención del agua necesaria. La obra asimismo demando movimientos de suelo precisos para rellenar los laterales del lago al instalarse en la bajada de la lomada. En este lago se celebraban fiestas y reuniones con juegos artificiales e inclusive se podía pasear en un barco a vapor, el "San Cipriano".

\section{Conclusiones}

Es incuestionable que los diseños de los patios, parques y jardines de San José dan testimonio de un período del paisaje construido por el hombre en Argentina y de la excentricidad de un personaje original y pionero. Urquiza edificó su morada y sus prados con estilo europeo inculcando un profundo respeto por la naturaleza, siendo un legado no tan conocido del caudillo entrerriano.

Sus amplios conocimientos de la idiosincrasia del campesino entrerriano, vinculado a la ganadería extensiva y al desconocimiento de las prácticas agrícolas, lo llevaron a proponer un cambio de conciencia basándose en la educación y en acciones concretas:

...siendo gobernador de Entre Ríos en 1851, implantó obligatoriamente en las escuelas primarias la enseñanza práctica de la agricultura..., Asimismo en 1854, siendo presidente de la Confederación Argentina, dictó una resolución de gobierno por la que obligaba a todos los estancieros de Entre Ríos con mas de cien cabezas de ganado a plantar obligatoriamente treinta árboles útiles por año, estableciendo un listado de especies aclimatadas"13.

Del mismo modo Urquiza reconoció la falta de bibliografía en el tema y mandó a imprimir libros sobre prácticas agrícolas, textos de Antonio E. Caravia en Montevideo y Toribio Arauz en Buenos Aires.

Esta investigación deja abiertas diversas pautas de trabajo, siendo el inicio del estudio sistemático del diseño y de las especies vegetales utilizadas, como también del paisaje construido en el siglo XIX en los comienzos de la historia argentina. Su valoración patrimonial debe alcanzar no solo al cuidado de la construcción arquitectónica, sino también, a la naturaleza y al diseño allí montado proponiendo estudios, investigaciones y reconstrucciones históricas de los jardines. 


\section{Notas}

1 Heit, Marta A. (2000). Palacio San José Patrimonio Botánico, Plan de publicación del Museo serie I: Catálogos, Museo y Monumento Nacional Justo José de Urquiza, Concepción del Uruguay, Provincia de Entre Ríos, República Argentina, página 9.

2 Ibídem, página 10.

3 Ibídem, página 10.

4 Falcao Ichaso, Carmen Lúcia (2002). Catálogo del Jardín Botánico de Río de Janeiro, Fundacao Andorinha Púrpura, patrocinio del gobierno de Canadá.

5 Contín, Mabel Irma (2000). Los parques de estancias, Una aproximación a la historia de la arquitectura paisajista argentina, De la ciudad al parque de estancia, Laboratorio de Investigación del Territorio y el Ambiente, Comisión de Investigación Científica, Dirección General de Cultura y Educación de la Provincia de Buenos Aires, impreso en Entrecomillas S. R. L. Calle 6 No 502/506, La Plata, Argentina, página 77.

6 Heit, Marta A. (2000). Palacio San José Patrimonio Botánico, op. cit., página 18.

7 de Dios Muños, Juan (2002). Plantas cultivadas en el Palacio San José en vida del General Justo José de Urquiza, Universidad Nacional de Entre Ríos, EDUNER, Concepción del Uruguay, Entre Ríos, Argentina, pagina 12.

8 El Uruguay (1867) Diario de la Tarde, Prensa Nacional, Fiesta de San José, Martes 2 de abril, Año XI Nº 2051 Entre Ríos. 9 Páez de la Cadena, Francisco (1998). Historia de los estilos en jardinería, editorial ISTMO S. A., Madrid, España, página 131.

10 Heit, Marta A. (2000). Palacio San José Patrimonio Botánico, op. cit., página 27.

11 Contín, Mabel Irma (2000). Los parques de estancias, op. cit., página 76 y 77.

12 “Palacio San José", Folleto del Museo y Monumento Nacional Justo José de Urquiza, Entre Ríos, Secretaria de Cultura y Comunicación, Dirección Nacional de Patrimonios Museos y Arte, Presidencia de la Nación.

13 de Dios Muños, Juan (2002). Plantas cultivadas en el Palacio San José en vida del General Justo José de Urquiza, op. cit., páginas 9 y 10.

\section{Bibliografía}

Contín, Mabel Irma (2000). Los parques de estancias, Una aproximación a la historia de la arquitectura paisajista argentina, De la ciudad al parque de estancia, Laboratorio de Investigación del Territorio y el Ambiente, Comisión de Investigación Científica, Dirección General de Cultura y Educación de la Provincia de Buenos Aires, impreso en Entrecomillas S. R. L. Calle 6 No 502/506, La Plata, Argentina.

de Dios Muños, Juan (2002). Plantas cultivadas en el Palacio San José en vida del General Justo José de Urquiza, Universidad Nacional de Entre Ríos, EDUNER, Concepción del Uruguay, Entre Ríos, Argentina.

El Uruguay (1867). Diario de la Tarde, Prensa Nacional, Fiesta de San José, Martes 2 de abril, Año XI Nº 2051 Entre Ríos. Falcao Ichaso, Carmen Lúcia (2002). Catálogo del Jardín Botánico de Río de Janeiro, Fundacao Andorinha Púrpura, patrocinio del gobierno de Canadá.

Heit, Marta A. (2000). Palacio San José Patrimonio Botánico, Plan de publicación del Museo serie I: Catálogos, Museo y Monumento Nacional Justo José de Urquiza, Concepción del Uruguay, Provincia de Entre Ríos, República Argentina

Jellicoe, Geoffrey y Susan (1995). El paisaje del hombre, la conformación del entorno desde la prehistoria hasta nuestros días, Editorial Gustavo Gili S. A., Barcelona, España.

Macchi, Manuel E. (1997). Palacio San José, Museo y Monumento Nacional “Justo José de Urquiza”, Artes Gráficas Yusty S. R. L., Concepción del Uruguay, Entre Ríos, Argentina.

Macchi, Manuel E. (1974). Normalísimo argentino: la escuela normal de Concepción del Uruguay en su centenario 1873-1973, acción inicial de Urquiza, Editorial Castelvi, Santa Fe, Argentina. 
Navarro, Angel Miguel (1986). El jardín de Versalles, servicios Bibliográficos S. A., Buenos Aires, Argentina.

Páez de la Cadena, Francisco (1998). Historia de los estilos en jardinería, editorial ISTMO S. A., Madrid, España.

"Palacio San José" (2002). Folleto del Museo y Monumento Nacional Justo José de Urquiza, Entre Ríos, Secretaria de Cultura y Comunicación, Dirección Nacional de Patrimonios Museos y Arte, Presidencia de la Nación.

Tiscornia, Bartolomé (2002). Club del Progreso, 1852-2002: sesquicentenario, Ediciones Lumiere, Buenos Aires, Argentina.

Summary: The Palacio San José, property of General Urquiza in Entre Ríos, has left testimonies of the landscaping history of XIX century in Argentina. Their parks and gardens are the evidence of a period where the reproduction of European landscaping models in America marked a time. The symmetrical composition of the palace conformed diverse gardens: two inner patios, the french garden, the backward park, the exotic park and the artificial lake; everything arranged proportionally to the east-west axis proposed by the construction. Here arise the hypothesis in relation to the 'english garden ' denomination and various hints are detected of a Tuscan disposition more than a French one. Also its legacy extends to the botanical scope, since San José were one of the most important centers of acclimatization of vegetal species of the country. Vegetation and originating seeds from Brazil, Paraguay, Montevideo, Buenos Aires and Europe arrived up to here, as gifts or purchases of General Urquiza, that valued and promoted agriculture and botanical education in its province. The vegetal composition of the gardens and species that formed the gardens of the Estancia San Jose are a national patrimony that deserves to be investigated.

Key words: Urquiza - Palacio San José - historical Gardens - landscaping Patrimony - Acclimatization of species.

Resumo: O Palacio San José, propriedade do General Urquiza em Entre Ríos, deixou depoimentos da história paisagística do século XIX em Argentina. Seus parques e jardins são a evidência de um período onde a reprodução de modelos paisagísticos europeus em América marcaram uma época. A composição simétrica do palácio conformou diversos jardins: os dois pátios interiores, o jardim francês, o parque posterior, o parque exótico e o lago artificial; tudo disposto proporcionalmente ao eixo este-oeste proposto pela construção. Aqui apresenta-se uma hipótese em relação à denominação do jardim inglês e se dão pautas que apontam a uma disposição toscana mais do que francesa. Além disso o seu legado estende-se ao âmbito botânico, dado que San José foi um dos mais importantes centros de aclimataçao de espécies vegetais do país. Chegavam até aqui vegetação e sementes provenientes de Brasil, Paraguai, Montevideo, Buenos Aires e Europa, de obséquio ou compras do próprio Urquiza, quem valorizava e fomentava como Governador a agricultura e a educação botânica em sua província. A composição dos jardins e as espécies vegetais que formavam os jardins do Palacio San José são um património nacional que merece seja pesquisado.

Palavras chave: Urquiza - Palacio San José - jardins históricos - património paisagístico - aclimataçao de espécies.

* Licenciado en Planificación y Diseño del Paisaje Universidad de Buenos Aires. Docente Titular de Cátedra de Taller Integral en la Universidad de Palermo. Docente de Historia de la Arquitectura Paisajista en la Universidad de Buenos Aires. Docente Titular de Cátedra de Material Vegetal en la Universidad de Belgrano. Coordinador de Buenos Aires de la Red Argentina del Paisaje. Publicó diversos artículos de la temática, en Argentina y en el exterior. Se desempeña como profesional en el área privada y docencia. 